\title{
FUNDAMENTAÇÃO DA DECISÃO JUDICIAL DO ARTIGO 489, §1 NOVO CÓDIGO DE PROCESSO CIVIL: O PAPEL DA MAGISTRATURA NA CONSTRUÇÃO DO DIREITO
}

Reginaldo Souza Novaes

Universidade do Oeste Paulista - UNOESTE, Curso de Direito, Presidente Prudente, SP. E-mail: reginaldo novaes@hotmail.com

\section{RESUMO}

O presente estudo tem como foco a interpretação do artigo 489, §10 do novo Código de Processo Civil (NCPC), portanto, são trazidos aqui os argumentos de como é e/ou pode/deve ser elaborada uma fundamentação/motivação judicial (pelos magistrados), diante da sua importância no direito. Dentro deste objeto da fundamentação das decisões judiciais é que este estudo foi elaborado, no sentido de participar da discussão que permeia esse tão importante instituto jurídico, que teve peso inflado pela vigência do novo Código de Processo Civil, visando assim uma ideia de decisão jurídica válida e completa, mediante cumprimento do papel do juiz na construção de decisões, e por consequência na construção do direito, nos ditames do artigo ora analisado. A metodologia aplicada foi hipotética dedutiva.

Palavras-chave: Fundamentação Judicial. Artigo 489 §1으 do CPC. Ativismo Judicial

\section{FUNDAMENTATION OF JUDICIAL DECISION OF ARTICLE 489, \$1 NEW CODE OF CIVIL PROCESS: THE ROLE OF MAGISTRATING IN THE CONSTRUCTION OF LAW}

\begin{abstract}
The present study focuses on the interpretation of article 489, $\S 1$ of the new Code of Civil Procedure (NCPC), therefore, the arguments of how and / or can / should be elaborated a reasoning / motivation judicial (by the magistrates ), given its importance in law. Within this object of the reasoning of the judicial decisions is that this study was elaborated, in order to participate in the discussion that permeates this so important legal institute, that had inflated weight by the validity of the new Code of Civil Procedure, aiming at an idea of valid legal decision and complete, by fulfilling the role of the judge in the construction of decisions, and consequently in the construction of the right, in the dictates of the article now analyzed. The applied methodology was hypothetical deductive.
\end{abstract}

Keywords: Judicial Grounds. Article 489, §1ํㅡ, CPC. Judicial Activism. 


\section{INTRODUÇÃO}

No estudo sobre a motivação e a fundamentação encontra-se que apesar do aparente sinônimo essas palavras destoam em seus núcleos, afirma-se isto pelos estudos de Kochem (2016), que em pesquisa etimológica teve o seguinte entendimento:

(...)Conforme o dicionário de língua portuguesa Houaiss, motivo significa "razão de ser, a causa de qualquer coisa", "o que põe alguém em prontidão para a ação; incentivo, motivação"; "que origina, causa, determina". Motivação, de seu turno, significa "ato ou efeito de motivar", "motivo, causa" e, especificamente na linguagem técnica da psicologia, "conjunto de processos que dão ao comportamento uma intensidade, uma direção determinada e uma forma de desenvolvimento próprias da atividade individual". Motivado é o "que tem motivo, causa ou fundamento; fundado, justificado".(...) (Kochem, 2016, p.3)

Acima Kochem aproxima a figura da motivação à característica da subjetividade que é impressa numa decisão, diferenciando-a da fundamentação, por ter essa segunda palavra maior ligação com uma base objetiva, no caso por meio de parâmetros jurídicos:

(...) fundamento significa "conjunto de princípios a partir dos quais se pode fundar ou deduzir um sistema, um agrupamento de conhecimentos", "base sólida que legitima ou autoriza algo; motivo, razão" e, especificamente na linguagem técnica da construção, "base, alicerce". Fundamentação significa "ato ou efeito de fundamentar(-apoiar-se), apoiar(-se), documentar(-se)" e fundamentar significa "apoiar(-se) em fundamentos; fundar(-se), documentar(-se), justificar(-se)", e, especificamente ao campo da construção, "lançar os fundamentos ou alicerces de; fundar". O mesmo dicionário tem um significado específico para o verbete fundamentar para o direito processual, constando "demonstrar através da lei, da doutrina, da jurisprudência, ou de provas (aquilo que a parte alega em juízo) com o fim de obter uma decisão favorável”. (...) (Kochem, 2016, p.3)

Motivação pode, nesta visão, ser lida como o caminho racional pelo qual a decisão foi construída, sendo passível de influências incompatíveis com a utopia do princípio do juiz natural, mas inerentes ao homem. Já a fundamentação é o que resguarda, em última análise, a expectativa de segurança jurídica, por ser advinda de fontes conhecidas e pré-estabelecidas em nosso ordenamento jurídico do atual Estado Democrático de Direito.

Kochem (2016) finda o aspecto desta diferenciação afirmando haver na atividade de prestação jurisdicional o vínculo humano, com suas afeições políticas, sociais, ideológicas e jurídicas, mas conclui seu estudo num sentido amplo: “(...)tenha como maior valor a recondutibilidade ao ordenamento jurídico. Com isso, quer parecer, cumpre-se a regra básica decorrente do princípio do Estado de Direito segundo o qual o que governa os homens deve ser o direito, não outros homens". (Komche, 2016, p.6).

Qualquer resposta judicial que emane caráter decisório é uma decisão judicial, que deve ter sua fundamentação e motivação adequada à justiça no caso concreto. A decisão pode ser de primeiro grau ou das instâncias superiores, pode ser monocrática ou colegiada.

O Estado, portanto, decide, resolve e assim o deve fazer dentro dos ditames legais, dentro, sobretudo das garantias legais, valendo-se de todo o aparato da chamada máquina judiciária, aplicando as normas extraídas das leis, para que haja a igualdade devida entre as partes envolvidas, que transcorra no devido processo legal, com a discussão do caso concreto, afim do justo processo, inclusive quando o próprio Estado for conflitante com o jurisdicionado, já que o juiz deve ser neutro e seguir os princípios que moldam o direito. A professora Ada 
Grinover ensina que o Estado deve seguir os princípios garantidores da justiça, citando que o juiz deve ser o natural, em suas palavras:

\begin{abstract}
a imparcialidade do juiz, mais do que simples atributo da função jurisdicional, é vista hodiernamente como seu caráter essencial, sendo o princípio do juiz natural erigido em núcleo essencial do exercício da função. Mais do que direito subjetivo da parte e para além do conteúdo individualista dos direitos processuais, o princípio do juiz natural é garantia da própria jurisdição, seu elemento essencial, sua qualificação substancial. Sem o juiz natural, não há função jurisdicional possível (GRINOVER, 2004, p. 52 e 53)
\end{abstract}

Com esta reflexão, objetiva-se com o presente artigo demonstrar que para uma decisão ser natural e adequada é necessário o respeito às bases principiológicas do direito, de tal forma que o princípio do juiz natural é um modo de alicerçar a jurisdição pela ausência de juízos de exceção.

\title{
METODOLOGIA
}

$\mathrm{Na}$ obtenção de dados da presente discussão, foi utilizada metodologia indutiva bibliográfica, abrangendo pesquisas de forma a levantar prismas, contextualizar e discutir, de forma crítica, sobre o tema citado, com base em levantamento bibliográfico de doutrinas jurídicas e portarias normativas afins, para leitura e fichamento, de forma intrinsecamente reflexiva, por considerar que a nossa hipótese versa em discutir fundamentos de existência do objeto. A discussão emprega o método hipotético dedutivo, avaliando as posições que sustentam (ou não) o objeto, de forma a buscar o confronto, a fim de analisá-lo com auxílio da dialética.

\section{RESULTADO}

O princípio que talvez seja o mais elevado em aplicabilidade e necessidade dentro de qualquer questão levada à máquina judiciária é o do devido processo legal, que envolve em complexidade todo o aparato disponível ao Estado e as partes, para que possam operar o direito dentro de qualquer procedimento necessário para cessar litígios. A fundamentação, como parte deste processo legal deve ser de tal modo que a sua composição torne útil à decisão dada ao caso concreto.

O direito é tanto complexo quanto uno, por ser um produto humano e inerente a todos, sem que possa se falar de ramos que existam isolados no direito. Não existe, por exemplo, a garantia de que um resultado no direito penal não produza efeitos civis, nem o contrário; enfim, o direito é uma ciência, um objeto humano complexo, e a fundamentação da decisão é essência em qualquer decisão jurisdicional, que a válida e a torna legítima, finalizando assim cada caso, em que o poder/dever do Estado for invocado para decidir pelas partes, atribuindo segurança jurídica à decisão, perfazendo a coisa julgada.

Qualquer decisão em processo judicial há de ter contornos pela lente constitucional, é ai elementar a feitura da fundamentação, numa argumentação que se amolde aos princípios Constitucionais. Apesar desta primeira análise, que perfaz o nosso sistema democrático, donde o juiz não pode, à princípio, criar o direito, devemos em tempo, fazer uma análise mais profunda, não necessariamente tão técnica, mas em caráter objetivo sobre a atividade jurisdicional.

O poder executivo tem, por exemplo, o condão de editar as chamadas medidas provisórias, já o poder judiciário é autônomo para execução em âmbito da administração da máquina judiciária, assim como poder legislativo o faz com seu orçamento interno, porém este 
último também faz papel judiciário, nas ocasiões em que, por exemplo, julga os casos de cassação e afins de seus integrantes.

Percebe-se que todos os poderes apesar da separação sistêmica, possuem atuações que não são em essência ligadas a natureza do poder central que lhe é natural o dever de exercer. Dentre estas atuações é de destaque a atuação do poder judiciário no âmbito legislativo. O princípio do livre convencimento motivado permitiu isso, conforme ensina Lenio Streck:

(...)O direito processual brasileiro se apega desde antanho ao livre convencimento motivado, como se verifica no CPP/1941 (arts. 155 e 200) e no CPC/1939 (art. 118). O $\mathrm{CPC} / 1973$ manteve-se preso à tradição no emblemático art. 131: "O juiz apreciará livremente a prova, atendendo aos fatos e circunstâncias constantes dos autos, ainda que não alegados pelas partes; mas deverá indicar, na sentença, os motivos que the formaram o convencimento" (Redação dada pela Lei no 5.925, de 01/10/1973). (...) Na práxis jurídica, costumava se considerar o juiz livre para agir (ou se omitir) dentro do processo, não existindo um direito da parte com relação a isso, e sim uma sujeição dela ao poder estatal. (...) Ambos ficam bastante aquém do que seria o paradigma democrático de processo.(...)“o juiz é o destinatário da prova”, que se deve ter "confiança no juiz da causa", que "o juiz é o dono do processo", que "o juiz decide conforme sua consciência", que "não está obrigado a enfrentar todos os argumentos das partes", ou que simplesmente "discorda" deles, que "nada há a esclarecer", que "mantém a decisão por seus próprios fundamentos" e etc. Alguns invocam até um "direito de julgar" que não pode ser cerceado. (STRECK, 2016, p. 4 e 5).

O mesmo autor ainda conclui sobre o livre convencimento, em que critica o emprego constante pelos juízes da filosofia para motivar decisões judiciais:

Falar em livre convencimento motivado é claramente articular sobre racionalidade, conhecimento, verdade, justificação, e nisso o discurso jurídico desliza sobre pressupostos filosóficos. A eliminação dos extremos é menos controversa, já que a íntima convicção e a prova tarifada flertam com concepções jusfilosóficas ultrapassadas (formas primitivas de realismo jurídico e positivismo jurídico). Só que entre um extremo e outro sobra muita coisa. (STRECK, 2016, p.5)

Considerando a explanação acima, tem-se que a filosofia quando presente na decisão com a específica finalidade de fundamenta-la, e não de ser a estrutura de motivação construtiva da argumentação, exacerba o conteúdo decisório, trazendo insegurança jurídica, e em consequência as decisões do tipo surpresa.

Multiplicidade de conflitos de interesses análogos, diante da superação do fundamento positivista de atribuir a um sistema legal rígido o fundamento da segurança jurídica, para se pautar a criação, interpretação e aplicação interpretação do Direito diante de valores positivados como princípios, confere ao intérprete uma margem de criação do direito no caso concreto. O Poder Judiciário (...) não tem unidade nem coerência, de modo que influências pessoais interferem nas decisões judiciais (DE MEDEIROS, 2017, p. 7-8)

Decisões viciadas que foram fundamentadas erroneamente são os motivos da crítica acima, haja vista que a magistratura, se utiliza por vezes de fundamentos vagos, genéricos ou indeterminados, que em análise se prestariam a responder qualquer caso e ao mesmo tempo nenhum, pela tênue linha racional que fica em aberto, que não demonstra enfrentamento dos argumentos (quando válidos) das partes.

\section{DISCUSSÃO}

A partir disso, passa-se então a discutir do aspecto acima, qual o limite do chamado ativismo judicial, pois, ao pretendermos discutir a decisão judicial, temos previamente que 
avaliar de que se vale, e do que se pode valer o magistrado para decidir, ou, mais especificamente, buscar compreender até onde pode ir a busca daquele pela extração normativa; Esta é, de antemão, uma questão que assola a academia de direito.

Trata-se de uma questão quase que dogmática; pelo raciocínio de que o ativismo judicial está estritamente ligado à separação dos poderes, elemento basilar de nossa atual estrutura de democracia, apenas por isso a atenção no tópico já é louvável, ora, o poder judiciário tem, em primeira análise do nosso sistema democrático, o poder/dever de dizer o direito, de regular sua aplicação mediante a finalidade de se obter justiça, e não de criá-lo, reserva está competente ao legislativo, entretanto este último por vezes se afasta do seu dever quando mais é necessário, deixando lacunas que acabam por atingir a operação do direito.

O professor Campilongo (2010) abstrai sobre o paradoxo da mistura de direito com política, que é o ponto de encontro dos poderes de legislar e operar o direito, faz uma dura crítica a forma como os cidadãos têm depositado fé na criatividade da magistratura, a qual tem ganhado terreno em busca de resultados por aqueles esperados, sem contudo atingi-los, já que para o professor citado é uma expectativa vinculada a uma visão ingênua e fictícia, em suas palavras:

A politização do direito, paradoxalmente, está associada tanto à perversão das garantias jurídicas dos cidadãos - os totalitarismos sempre "politizaram" o sistema jurídico - quanto à expansão das franquias democráticas - é justamente nas democracias que a independência da magistratura e a criatividade dos juízes ganham espaços. Além disso, a politização do direito - mais uma vez tanto nos regimes totalitários quanto nos democráticos - está associada à crença de que o sistema jurídico pode ser o instrumento privilegiado para a consecução dos objetivos da coletividade. Como se existisse, entre a vontade geral e o direito, mais do que a mera congruência entre escolhas valorativas e pautas de conduta, e como se houvesse, por parte do sistema jurídico, efetiva capacidade de implementação de relações causais no ambiente externo ao direito, num processo decisório unívoco e que, mecanicamente, conduzisse aos resultados esperados. Trata-se de uma visão ingênua da política e fictícia quanto ao direito.(CAMPINLONGO, 2010, p. 175-176, grifo nosso)

As lacunas no mundo jurídico, porém, não existem exclusivamente por escusas do poder legislativo. É razoável que o direito como reflexo da sociedade, não teria o condão de satisfazer, no aspecto da previsão normativa, a toda e qualquer situação em que seja invocado em discussão jurídica, pois, temos pretensões de tutela variadas, inéditas por vezes, seria surreal acreditar que a lei positivada resguarda em plenitude, a gama de possibilidades buscadas no judiciário, com segurança ao direito, neste diapasão:

O processo civil brasileiro é um procedimento em contraditório, que se desenvolve de forma isonômica perante o juiz natural, destinado a permitir a construção de decisões fundamentadas em tempo razoável sobre qualquer pretensão que se deduza em juízo (já que é garantido o acesso universal à justiça). (...) O modelo constitucional de processo civil brasileiro tem, entre seus princípios integrantes, o da segurança jurídica. Pois não há segurança jurídica sem previsibilidade das decisões judiciais, o que exige uma estabilidade decisória que só se consegue com a construção de um sistema de precedentes judiciais vinculantes (...) precedentes estabelecem uma padronização decisória que impede a formação de uma esquizofrenia jurisprudencial, decorrente da existência de uma miríade de decisões divergentes proferidas em casos iguais. É fundamental, para preservar-se a segurança jurídica e a isonomia, que casos iguais recebam decisões iguais. E isso só se consegue quando os juízes e tribunais respeitam não só as decisões dos tribunais que lhes sejam superiores (eficácia vertical dos precedentes), mas também as suas próprias decisões (eficácia horizontal dos precedentes). Pois o Código de Processo Civil busca regulamentar o modo como os precedentes exercerão essa eficácia vinculante, o que se impõe na busca por um processo mais isonômico e, por isso mesmo, mais democrático. (CAMARA, 2017, p. 2,) 
Pela lição acima, naquilo que se refere à segurança jurídica, pode ser entendido que ao fundamentar uma decisão, deve-se sistematicamente por em paralelo os nuances do direito, os antecedentes e consequentes à lide, para ver o direito como um sistema jurídico não dicotômico.

\section{CONCLUSÃO}

A motivação coerente e a boa fundamentação colocam além de legitimidade, o status de que as questões trazidas ao juízo dentro do processo foram devidamente enfrentadas. A própria Constituição Federal, em seu art.93, IX, estabelece que toda decisão deve ser fundamentada, sob pena de nulidade, porém, mesmo tratando-se de um direito constitucional, a jurisdição tem se ausentado, por diversos fatores, de melhor uso.

Assim houve necessidade de um reforço por meio de lei, e é aí que surge o tão discutido artigo 489, $\S 1^{\circ}$ o do Código de Processo Civil atual, que vem no sentido de dar negação à admissão como sentença às decisões não fundamentadas, refutando assim qualquer decisão que seja elaborada de uma das maneiras descritas em seus incisos.

O artigo exemplifica de forma incisiva, como não pode ser elaborada uma decisão, pois, se a decisão não pode ser considerada fundamentada, não há de ser uma decisão íntegra, mas viciada, caracterizando um error in procedendo, conforme o ensinamento de Alexandre Flexa:

Reconhecida a deficiência de fundamentação, a decisão estará eivada de error in procedendo, e deve o tribunal decretar sua nulidade. Sendo possível, outrossim, a aplicação à teoria da causa madura, desde que preenchidos os pressupostos do $\$ 3^{\circ}$, do art. 1.013 (enunciado n' 30J, do Fórum Permanente de processualistas Civis) que deve ser sanado para que o processo venha a contemplar sua utilidade. (FLEXA, 2016, p. 363).

A lição acima vem no sentido de que na atual carta processual civil a decisão deve ser construída pelo juiz em conformidade com a previsão do disposto no atigo 489 , § $1^{\circ}$ do CPC, sob pena de nulidade, a seguir o texto do dispositivo que é o foco deste estudo:

Artigo 489 (...)

$\S 1^{\underline{0}}$ Não se considera fundamentada qualquer decisão judicial, seja ela interlocutória, sentença ou acórdão, que:

I - se limitar à indicação, à reprodução ou à paráfrase de ato normativo, sem explicar sua relação com a causa ou a questão decidida;

II - empregar conceitos jurídicos indeterminados, sem explicar o motivo concreto de sua incidência no caso;

III - invocar motivos que se prestariam a justificar qualquer outra decisão;

IV - não enfrentar todos os argumentos deduzidos no processo capazes de, em tese, infirmar a conclusão adotada pelo julgador;

V - se limitar a invocar precedente ou enunciado de súmula, sem identificar seus fundamentos determinantes nem demonstrar que o caso sob julgamento se ajusta àqueles fundamentos;

$\mathrm{VI}$ - deixar de seguir enunciado de súmula, jurisprudência ou precedente invocado pela parte, sem demonstrar a existência de distinção no caso em julgamento ou a superação do entendimento.

V - se limitar a invocar precedente ou enunciado de súmula, sem identificar seus fundamentos determinantes nem demonstrar que o caso sob julgamento se ajusta àqueles fundamentos;

$\mathrm{VI}$ - deixar de seguir enunciado de súmula, jurisprudência ou precedente invocado pela parte, sem demonstrar a existência de distinção no caso em julgamento ou a superação do entendimento. (Brasil, Código de Processo Civil, 2015) 
Aparenta que o novo Código de Processo Civil transcreve nesse dispositivo a denotação daquelas falhas mais comuns que por vezes já foram encontradas nas ocasiões em que o juiz, investido no dever/poder do Estado, disse erroneamente o direito. Em análise percebe-se que neste artigo o legislador está dizendo exemplificadamente ao juiz, não decida sem fundamentar, sob pena de desqualificação e nulidade da decisão. O professor Fredie Didier ressalta os vícios que quando presentes tornam nulas as decisões proferidas:

Nos termos do art. 93, IX, da Constituição Federal, todo pronunciamento judicial há de ser devidamente fundamentado, sob pena de nulidade. A omissão, a contradição, a obscuridade e o erro material são vícios que subtraem da decisão a devida fundamentação. Para que a decisão esteja devidamente fundamentada, é preciso que não incorra em omissão, em contradição, em obscuridade ou em erro material.(DIDIER, 2016, p. 248)

Dentro do estudo da fundamentação da decisão judicial é de destaque a atuação do Juiz, sobretudo por ser este quem faz/deve fazer a fundamentação, atualmente o judiciário brasileiro vem de um período recente de prestígio perante a sociedade, muito em função dos recentes casos de investigações e julgamentos dos políticos e empresários poderosos, que por seus infelizes atos criminosos de corrupção foram condenados.

Não obstante, acima de qualquer julgamento isolado, o Judiciário deve prestigiar a confiança da sociedade, e a fundamentação é a melhor forma de atribuir legitimidade a decisão, de mostrar a sociedade que a justiça foi buscada, isto por ser a fundamentação importante ao ponto de vincular a decisão, ou seja, a decisão advém da fundamentação, que logo é sua nascente, que se não mais existir, ou se deixar de fazer sentido, ocasionará a desestabilização da decisão, como se fosse um muro sem alicerce, tende a cair.

\section{REFERÊNCIAS}

BRASIL, CONSTITUIÇÃO (1.988). Constituição da República Federativa do Brasil. Brasília: Senado Federal, 1.988

BRASIL, CÓDIGO DE PROCESSO CIVIL. Código de Processo Civil Brasileiro. Brasília: Senado Federal, 2.015.

CÂMARA, Freitas, A. (01/2017). O Novo Processo Civil Brasileiro, 3ạ edição. Disponível em: < https://integrada.minhabiblioteca.com.br/\#/books/9788597009941/>. Acesso em: 10 maio. 2018.

CAMPILONGO, Celso Fernandes. Política Sistema Jurídico e Decisão Judicial, 2a edição. Saraiva, $12 / 2010$.

DE MEDEIROS, Marcelo Farina, Precedentes Obrigatórios, Isonomia na aplicação da lei. Disponível em: <https://marcelofmedeiros.jusbrasil.com.br/artigos/415051238/precedentesbrigatorios $>$.Acesso em 10 de maio. 2018

DIDIDER, Fredie. Curso de Direito Processual Civil. Meios de Impugnação às Decisões Judiciais e Processo nos Tribunais, 13 ed., Salvador, Juspodivm, v. 3, 2016.

DIDIDER, Fredie, et al. Novas Tendências do Processo Civil. Salvador, Juspodivm, vol. 2, 2016. 
FLEXA, Alexandre, Et Al. Novo Código de Processo Civil. Temas Inéditos. Mudanças e Supressões. Salvador, Juspodivm, 2015.

GRINOVER, Ada Pellegrini; FERNANDES, Antônio Scarance; GOMES FILHO. As Nulidades no Processo Penal. São Paulo: Ed. Revista dos Tribunais, 2004.

KOCHEM, Ronaldo Luis. A Fundamentação da Decisão Judicial: Objeto e Critérios de Controle. Dissertação de mestrado-UFRGS, Porto Alegre, 2016.

STRECK, Lenio Luiz. CUNHA, Leonardo Carneiro da. FREIRE, Alexandre. Comentários ao Código de Processo Civil. São Paulo: Saraiva, 2016. 